\title{
DETERMINAÇÃO DA CONCENTRAÇÃO INIBITÓRIA MÍNIMA DE CONSERVANTES ALIMENTARES PARA O CONTROLE DE SALMONELLA TYPHIMURIUM
}

R. D. FERREIRA ${ }^{1}$, R.A. SOARES ${ }^{2}$, L. A. CARVALHO ${ }^{3}$, G. A. SILVA ${ }^{4}$, C. A. OLIVEIRA ${ }^{5}$, G. ALVES E SILVA ${ }^{6}$

Instituto Federal de Educação, Ciência e Tecnologia do Sertão Pernambucano $0^{1-5}$, Instituto Federal de Educação, Ciência e Tecnologia do Mato Grosso ${ }^{6}$

ORCID ID: http://orcid.org/0000-0003-2900-0373 ${ }^{2}$

rodrigo.araujo@ifsertao-pe.edu.br ${ }^{2}$

DOI: $10.15628 /$ holos.2020.10069

\section{RESUMO}

A Salmonella é uma bactéria patogênica responsável por gastroenterites, sendo o principal agente de doenças de origem alimentar em várias partes do mundo, inclusive no Brasil. Visando inibir seu crescimento, pode-se utilizar conservantes como metabissulfito, bissulfito e benzoato de sódio, e o sorbato de potássio, que são amplamente empregados na preservação de alimentos. Estudos utilizando esses aditivos para inibição da Salmonella Typhimurium são escassos e, devido à sua importância para a segurança alimentar, objetivou-se determinar a Concentração Inibitória Mínima (CIM) dos conservantes, a fim de fornecer mais informações sobre a resistência da bactéria. Nas condições do experimento, os conservantes metabissulfito e bissulfito de sódio apresentaram maior atividade antimicrobiana contra a $S$. Typhimurium, ambos com CIM de $1.250 \mu \mathrm{g} \cdot \mathrm{mL}^{-1}$. Já os conservantes benzoato de sódio e sorbato de potássio necessitaram do dobro da quantidade para inibi-la, apresentando CIM de $2.500 \mu \mathrm{g} \cdot \mathrm{mL}^{-1}$ e $2.300 \mu \mathrm{g} \cdot \mathrm{mL}^{-1}$, respectivamente. Concentrações tão elevadas de conservantes se devem às condições do experimento, principalmente em relação ao $\mathrm{pH}$ do meio de cultura $(\mathrm{pH} \sim 7,3)$, já que estes conservantes são mais efetivos em condições ácidas.

PALAVRAS-CHAVE: Microbiologia, Segurança alimentar, Aditivos, Conservação.

\section{DETERMINATION OF THE MINIMUM INHIBITORY CONCENTRATION OF FOOD PRESERVATIVES TO CONTROL OF SALMONELLA TYPHIMURIUM}

\begin{abstract}
Salmonella is a pathogenic bacterium responsible for gastroenteritis, being the main agent of food-borne diseases in several parts of the world, including Brazil. In order to inhibit its growth, preservatives such as metabisulfite, bisulfite and sodium benzoate and potassium sorbate can be used, which are widely used in food preservation. Studies using these additives to inhibit Salmonella Typhimurium are scarce and, due to their importance for food safety, the objective was to determine the Minimum Inhibitory Concentration (MIC) of preservatives, in order to provide more information on
\end{abstract}

the resistance of the bacteria. Under the conditions of the experiment, the preservatives metabisulfite and sodium bisulfite showed greater antimicrobial activity against $S$. Typhimurium, both with MIC of $1,250 \mu \mathrm{g} \cdot \mathrm{mL}^{-1}$. The preservatives sodium benzoate and potassium sorbate required twice the amount to inhibit it, with MIC of 2,500 $\mu \mathrm{g} \cdot \mathrm{mL}^{-1}$ and $2,300 \mu \mathrm{g} \cdot \mathrm{mL}^{-1}$, respectively. Such high concentrations of preservatives are due to the conditions of the experiment, mainly in relation to the $\mathrm{pH}$ of the culture medium ( $\mathrm{Ph} \sim 7.3$ ), already these preservatives are more effective in acidic conditions.

KEYWORDS: Microbiology, Food safety, Additives, Conservation. 


\section{INTRODUÇÃO}

Uma das maiores preocupações da indústria de alimentos refere-se à segurança alimentar e, por isso, as Boas Práticas de Fabricação (BPF) são exigências mínimas a serem cumpridas para que um alimento possa ser considerado seguro. Complementarmente, a indústria utiliza também os aditivos químicos, principalmente os conservantes, importantes no controle microbiológico, sobretudo quando se trata de bactérias patogênicas.

A Agência Nacional de Vigilância Sanitária (ANVISA), em sua resolução RDC no 12 de 02 de janeiro de 2001, estabelece rígidos padrões microbiológicos para os alimentos, dentre estes, a ausência de Salmonella em $25 \mathrm{~g}$ (ou $\mathrm{mL}$ ) de produto (BRASIL, 2001). Dessa forma, esta bactéria é a que possui o padrão microbiológico mais rígido, indicando a severidade deste microrganismo.

A Salmonella é uma bactéria patogênica da família Enterobacteriaceae, responsável por gastroenterites que tem como sintomas febre, dor de cabeça, cólicas abdominais, diarreia, náuseas e as vezes vômito. É o principal agente de doenças de origem alimentar em várias partes do mundo, inclusive no Brasil (Silva et al., 2010), e cerca de 80,3 milhões de casos de salmoneloses de origem alimentar são relatados anualmente no mundo (Majowicz et al., 2010). A toxinfecção causada por essa bactéria ocasiona maior número de óbitos do que aquelas causadas por outros microrganismos (Rodrigues \& Salay, 2000) devido a sua elevada endemicidade, alta morbidade e dificuldades no controle (Santos et al., 2002).

Uma das formas para controlar o desenvolvimento de microrganismos é através do uso de conservantes. Estes compostos fazem parte de uma classe de aditivos alimentares capazes de eliminar, total ou parcialmente, os microrganismos, ou mesmo criar condições desfavoráveis ao seu crescimento. Os conservantes assumem papel fundamental na segurança alimentar, principalmente em países tropicais, onde as condições de temperatura e umidade são propícias ao desenvolvimento da maioria dos microrganismos. Além disso, as grandes distâncias entre os centros de produção e consumo, somado ao armazenamento muitas vezes inadequado, fazem dos conservantes um grande aliado na manutenção da vida útil dos alimentos.

Dentre os conservantes mais comumente utilizados em alimentos estão o benzoato, bissulfito e metabissulfito de sódio, e o sorbato de potássio. Quando usados dentro das recomendações dos órgãos competentes como a ANVISA, a Food and Drug Administration (FDA) e a Autoridade Europeia para a Segurança dos Alimentos (EFSA), não costumam apresentar efeitos colaterais relevantes.

Estudos utilizando estes aditivos para a inibição da S. Typhimurium são escassos e devido à sua importância para a segurança alimentar, objetivou-se determinar a Concentração Inibitória Mínima (CIM) in vitro destes conservantes, a fim de fornecer mais informações sobre a resistência desta bactéria. 


\section{REVISÃO BIBLIOGRÁFICA}

\subsection{Salmonella spp.}

A Salmonella é uma bactéria anaeróbia facultativa, Gram negativa, não produtora de esporos e tem a forma de bastonete curto (Silva et al., 2010). A maioria é móvel, com flagelos peritríquos, à exceção da S. Gallinarum e S. Pullorum (Lázaro et al., 2008; Cardoso \& Tessari, 2015). A temperatura ótima de crescimento é de aproximadamente $38{ }^{\circ} \mathrm{C}$ e a mínima de $5{ }^{\circ} \mathrm{C}$ (Jay, 2005). Como não formam esporos, são relativamente termossensíveis, podendo ser destruídas a $60{ }^{\circ} \mathrm{C}$, por 15 a 20 minutos (Forsythe, 2002). De acordo com Franco \& Landgraf (2005), o pH ótimo para multiplicação da Salmonella fica próximo de 7,0, e valores superiores a 9,0 e inferiores a 4,0 são bactericidas. Dependendo da natureza do ácido utilizado para acidificação, o pH mínimo pode subir para 5,5, e concentrações de sal superiores a 9\% não são toleradas por essa bactéria. A Salmonella também é capaz de formar biofilmes, que estão associados a maior resistência ao estresse ambiental (Steenackers et al., 2012; Yang et al., 2012).

As cepas mais frequentemente envolvidas nas doenças humanas são as de $S$. enterica subsp. enterica, que tem por habitat os animais de sangue quente e respondem por $99 \%$ das salmoneloses humanas (Silva et al., 2010). O principal habitat das salmonelas é o trato gastrintestinal de humanos e animais. Alguns poucos sorotipos são restritos a um hospedeiro, como Salmonella Typhi, $S$. Paratyphi A e C, e Salmonella Sendai em humanos; S. Abortusovis em ovinos; S. Choleraesuis em suínos; S. Dublin em bovinos; e S. Pullorum e S. Gallinarum em aves (Lázaro et al., 2008). Quando esses provocam doenças em humanos, o processo geralmente é invasivo e apresenta risco de morte. A maioria dos sorotipos, entretanto, tem um espectro de hospedeiros amplos e, tipicamente, provocam gastroenterites sem complicações e sem necessidade de tratamento. Os sintomas ocorrem entre 6 e 48 horas, incluindo febre, dor de cabeça, cólicas abdominais, diarreia, náuseas e as vezes vômito. A duração é de um ou dois dias, podendo prolongar-se dependendo do hospedeiro, da dose ingerida e da cepa de Salmonella envolvida (Silva et al., 2010).

Há divergências na literatura quanto à dose infectiva, mas segundo Silva et al. (2010), ela estaria entre 15 e 20 células. Para Lázaro et al. (2008), entretanto, ela varia de $10^{5}$ a $10^{8}$ células, porém em pacientes imunocomprometidos, doses menores que $10^{3}$ para alguns sorovares seria suficiente para causar a doença. Idosos e crianças podem sofrer desidratação severa e pacientes com doenças imunodepressoras são atingidos por salmoneloses com uma frequência 20 vezes maior do que a população geral, sofrendo episódios recorrentes. Em $80 \%$ dos casos, as salmoneloses ocorrem individualmente e não em surtos explosivos (Silva et al., 2010).

Franco \& Landgraf (2005), ao se referirem ao mecanismo de patogenicidade da Salmonella, comentam que as infecções começam na mucosa do intestino delgado e do cólon. A bactéria atravessa a camada epitelial intestinal e alcança a lâmina própria, onde proliferam. Em seguida são fagocitadas pelos monócitos e macrófagos, resultando em resposta inflamatória. Ao contrário do 
que ocorre na febre tifóide e nas entéricas, nas enterocolites a penetração de Salmonella fica limitada à lâmina própria. Nestes casos, raramente se observa septicemia ou infecção sistêmica, ficando a infecção restrita à mucosa intestinal. A resposta inflamatória está relacionada também à liberação de prostaglandinas, que são estimuladoras de adenilciclase, resultando em um aumento de secreção de água e eletrólitos, provocando diarreia aquosa.

A presença de Salmonella em alimentos é um grande problema de saúde pública em todo o mundo. Ela pode estar presente em fezes contaminadas, manipuladores e equipamentos de alimentos, insetos, roedores, além da água e do solo (Mattick et al., 2000; Shinohara et al., 2008).

A Salmonella enterica subespécie enterica sorotipo Typhimurium (S. Typhimurium) é um sorotipo ubiquitário amplamente disseminado na natureza e de grande importância em saúde pública (Tavechio et al., 2002). A S. Typhimurium, assim como a S. Enteritidis, estão altamente associadas a casos de septicemia e infecções localizadas, inclusive no sistema nervoso central (BRASIL, 2011), e apresenta uma considerável multirresistência à antimicrobianos (Helms et al., 2005).

\subsection{Conservantes alimentares}

A Portaria no 540, da Secretaria de Vigilância em Saúde (SVS) do Ministério da Saúde (MS), define aditivo alimentar como qualquer ingrediente adicionado intencionalmente aos alimentos, sem propósito de nutrir, com o objetivo de modificar as características físicas, químicas, biológicas ou sensoriais, durante a fabricação, processamento, preparação, tratamento, embalagem, acondicionamento, armazenagem, transporte ou manipulação de um alimento (Brasil, 1997). Dentre as classes de aditivos, destaca-se a dos conservantes, que são formados por substâncias que impedem ou retardam a alteração dos alimentos provocada por microrganismos ou enzimas.

Nos alimentos, tanto in natura como nos processados, a multiplicação microbiana ocorre em função do tipo de alimento e das condições ambientais (Jay, 2005). O processo de conservação baseia-se na destruição total ou parcial dos microrganismos capazes de alterar o alimento, ou na modificação ou eliminação de um ou mais fatores que são essenciais para a sua multiplicação, de modo que o alimento não se torne propício ao desenvolvimento microbiano (Evangelista, 2008). Também podem ser incorporadas aos alimentos substâncias inibidoras como os conservantes alimentares.

Os conservantes, também conhecidos como agentes antimicrobianos, costumavam prolongar o prazo de validade dos alimentos, protegendo-os contra a deterioração causada por microrganismos como fungos e bactérias (Lidon \& Silvestre, 2007). Entretanto, é vetado o uso de aditivos em alimentos quando houver evidências ou suspeitas de que o mesmo não é seguro para o consumo humano; interferir sensível e desfavoravelmente no valor nutritivo do alimento; servir para encobrir falhas no processamento e/ou manipulação; encobrir alteração ou adulteração da 
matéria-prima ou do produto elaborado; ou induzir o consumidor ao erro, engano e confusão (Brasil, 1997).

O dióxido de enxofre e sais de enxofre, que incluem os sulfitos, bissulfitos e metabissulfitos, de sódio e de potássio, são aditivos multifuncionais, atuando na prevenção do escurecimento enzimático e não enzimático, no controle microbiológico, como antioxidante e agente branqueador (Damodaran, Parkin, \& Fennema, 2010; Oliveira et al., 2008). Sulfito de sódio, bissulfito de sódio e metabissulfito de sódio possuem as seguintes fórmulas químicas e identificação pelo International Numbering System: $\mathrm{Na}_{2} \mathrm{SO}_{3}$ (INS 221), $\mathrm{NaHSO}_{3}$ (INS 222) e $\mathrm{Na}_{2} \mathrm{~S}_{2} \mathrm{O}_{5}$ (INS 223), respectivamente. São comumente utilizados na fabricação de vinhos, sucos e bebidas carbonatadas, além de frutas desidratadas por seu efeito antimicrobiano sobre bactérias acéticas, além de atuarem como agentes inibidores de mofo e levedura (FILLA, 2016). A IDA (Ingestão Diária Aceitável) não deve ultrapassar $0,7 \mathrm{mg} . \mathrm{Kg}^{-1}$ de peso corpóreo/dia, expressa em $\mathrm{SO}_{2}$ (Favero et al., 2011).

Atualmente, os sorbatos são o terceiro maior grupo de conservantes antimicrobianos nas indústrias alimentícia e farmacêutica, atrás apenas dos parabenos e benzoatos (Nemes et al., 2020). O sorbato de potássio (INS 202), assim como o ácido sórbico (INS 200), são conservantes utilizados nos mais diversos tipos de alimentos tais como bebidas (sumos de fruta, vinho e sidra), pastelaria e padaria parcialmente cozida, queijos, frutas e legumes em conserva ou cristalizadas, azeitonas, compotas e geleias, dentre outros (Silva \& Lidon, 2016). Na quantidade comumente utilizada não costuma apresentar efeitos colaterais relevantes, porém foram descritas possíveis alergias, geralmente urticária (ABDULMUMEEN et al., 2012). Sua fórmula química é $\mathrm{C}_{6} \mathrm{H}_{7} \mathrm{KO}_{2}$, e a IDA do sal

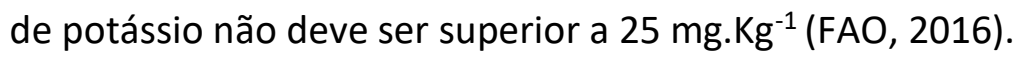

O benzoato de sódio (INS 211) é um conservante alimentar obtido a partir da neutralização do ácido benzoico por hidróxido de sódio, e apresenta a fórmula química $\mathrm{C}_{6} \mathrm{H}_{5} \mathrm{COONa}$. Embora o ácido benzoico não dissociado seja o agente antimicrobiano mais efetivo, usa-se preferencialmente o benzoato de sódio por ser cerca de 200 vezes mais solúvel em água. Por conferir um gosto forte e apimentado, seu uso é restringido a certo número de produtos, sendo as bebidas carbonatadas sua principal aplicação (FIB, 2011). Também é usado em salada de frutas, geleias, doces, margarinas, balas, tortas de frutas e molhos. Este conservante está listado entre os aditivos considerados GRAS (Generally Recognized As Safe) pela FDA, podendo estar presente em alimentos com uma concentração de até 1000 ppm (Chipley, 2005). O ácido benzoico e seus sais não apresentam efeitos tóxicos, apesar de raramente intolerâncias como asma e urticárias já terem sido relatadas. De acordo com as estimativas fornecidas pelo Comitê Conjunto da FAO/OMS sobre Aditivos Alimentares, a IDA do benzoato de sódio não deve exceder $5 \mathrm{mg} \cdot \mathrm{Kg}^{-1}$, expresso em ácido benzoico (WHO, 2016). 


\section{METODOLOGIA}

O experimento foi realizado no Laboratório de Físico-química/Microbiologia de alimentos do Instituto Federal de Educação, Ciência e Tecnologia do Sertão Pernambucano, campus Salgueiro.

\subsection{Compostos antimicrobianos}

Os conservantes alimentares testados foram o sorbato de potássio, benzoato de sódio, bissulfito de sódio e metabissulfito de sódio. Todos os conservantes fornecidos pela Synth ${ }^{\circledR}$ (São Paulo, SP) e com pureza superior a 98\%. A escolha destes conservantes se deveu a reconhecida eficiência contra um grande espectro de microrganismos e pelo baixo custo, além de serem permitidos pela legislação brasileira para uso em alimentos.

\subsection{Cepa bacteriana e meios de cultura}

A cepa utilizada foi a Salmonella Typhimurium S190, cedida pelo Laboratório de Microbiologia de Alimentos da Universidade Federal de Lavras. Para as análises microbiológicas foram utilizados os meios Tryptic Soy Broth (TSB) e Tryptic Soy Agar (TSA) da HiMedia ${ }^{\circledR}$ (Mumbai, Índia), ágar Rambach da Merck $^{\circledR}$ (Darmstadt, Alemanha) e água peptonada tamponada da Kasvi ${ }^{\circledR}$ (São José do Pinhais, Paraná).

\subsubsection{Manutenção e padronização da cepa de Salmonella}

A manutenção e padronização da cepa de S. Typhimurium S 190 foi realizada conforme Oliveira, Soares \& Piccoli (2013). A bactéria foi estocada a $-18{ }^{\circ} \mathrm{C}$ em microtubos contendo meio de congelamento [glicerol $(150 \mathrm{~mL})$, peptona $(5 \mathrm{~g})$, extrato de levedura $(3 \mathrm{~g}), \mathrm{NaCl}(5 \mathrm{~g}), \mathrm{H} 2 \mathrm{O}(1.000 \mathrm{~mL})$ $\mathrm{pH}(7,2 \pm 0,2)$ ]. Para manter a cultura viável, foram realizadas durante o experimento repicagens, nas quais alíquotas foram transferidas de microtubos para tubos, contendo caldo TSB e incubados por 24 horas a $37^{\circ} \mathrm{C}$. Após o cultivo, $1 \mathrm{~mL}$ da cultura foi novamente acondicionado em microtubos estéreis e centrifugados a 5000 rotações por minuto (rpm) durante 5 minutos. Retirado o sobrenadante, o conteúdo foi novamente recoberto com meio de congelamento e acondicionado a $-18^{\circ} \mathrm{C}$.

Para a padronização das contagens do número de unidades formadoras de colônias (UFC), foi elaborada a curva de crescimento da cultura bacteriana. Alíquotas da cultura de S. Typhimurium foram transferidas para erlenmeyers contendo caldo TSB e incubadas a $37^{\circ} \mathrm{C}$, com a monitoração do crescimento a cada hora, por meio de espectrofotometria $(600 \mathrm{~nm})$ e plaqueamento em meio TSA. O procedimento foi repetido até que as leituras dos valores ficassem constantes, garantindo, assim, a fase estacionária, e determinando o $\log \mathrm{UFC} / \mathrm{mL}$. Este procedimento manteve o número de UFC no inóculo da cultura reveladora sobre controle.

\subsubsection{Atividade antimicrobiana in vitro dos conservantes}

A determinação da concentração inibitória mínima (CIM) dos conservantes sobre a $S$. Typhimurium foi realizada empregando-se a técnica de microdiluição em caldo em microtubos estéreis, de acordo com o NCCLS M7-A6 (NCCLS, 2003), com modificações. O meio de cultura TSB 
foi preparado e esterilizado em autoclave de acordo com as recomendações do fabricante, e em seguida os conservantes foram nele diluídos $(p / v)$, obtendo-se as concentrações apresentadas na Tabela 1.

Tabela 1: Concentrações testadas para a determinação da CIM de conservantes alimentares.

\begin{tabular}{c|c|c|c|c|c|c|c}
\hline Conservantes alimentares & \multicolumn{7}{|c}{ Concentração ( $\left.\mu \mathrm{g} \cdot \mathrm{mL}^{-1}\right)$} \\
\hline Sorbato de potássio & 2.500 & 2.300 & 2.100 & 1.900 & 1.700 & 1.500 & 1.300 \\
\hline Benzoato de sódio & 2.500 & 2.300 & 2.100 & 1.900 & 1.700 & 1.500 & 1.300 \\
\hline Metabissulfito de sódio & 1.250 & 1.150 & 1.050 & 950 & 850 & 750 & 650 \\
\hline Bissulfito de sódio & 1.250 & 1.150 & 1.050 & 950 & 850 & 750 & 650 \\
\hline
\end{tabular}

Um volume de $1.000 \mu \mathrm{L}$ do meio de cultura com os conservantes nas diferentes concentrações foram acondicionados em microtubos e, em seguida, foram adicionados $67 \mu \mathrm{L}$ do inóculo padronizado $\left(10^{8} \mathrm{UFC} \cdot \mathrm{mL}^{-1}\right)$ de $S$. Typhimurium, com exceção do controle, que continha apenas o meio de cultura com os conservantes, sem o inóculo. Os microtubos foram incubados a 37 ${ }^{\circ} \mathrm{C}$ por $24 \mathrm{~h}$ e analisados quanto a presença ou não de turvação no meio TSB. Assim, o microtubo contendo a menor concentração do conservante no qual não havia crescimento visível (SCV), ou seja, sem turvação do meio, foi considerado a CIM (Figura 1). O experimento foi feito com três repetições sendo as amostras realizadas em triplicata.

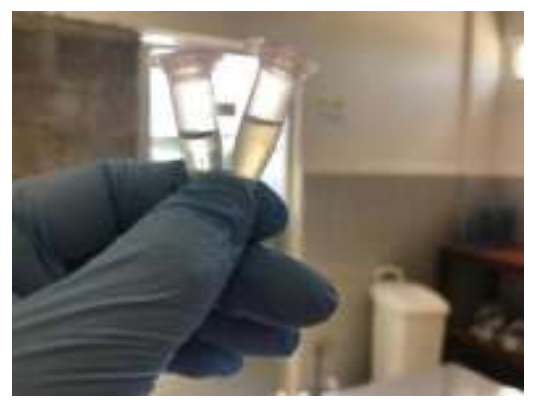

Figura 1: Teste de determinação da CIM. Da esquerda para a direita: microtubo sem crescimento visível (SCV) e com crescimento visível (CV) após incubação a $37^{\circ} \mathrm{C} / 24 \mathrm{~h}$.

\section{RESULTADOS E DISCUSSÃO}

A Tabela 2 apresenta o resultado da CIM dos conservantes testados. Observa-se que todos os conservantes inibiram o crescimento da $S$. Typhimurium em pelo menos uma das concentrações HOLOS, Ano 36, v.4, e10069, 2020 
testadas. Observa-se que os conservantes do grupo dos sulfitos (metabissulfito e bissulfito de sódio) foram os mais efetivos na inibição da S. Typhimurium, ambos apresentando CIM de $1.250 \mu \mathrm{g} . \mathrm{mL}^{-1}$. Jay (2005) relata que a ação bactericida dos sulfitos em microrganismos ocorre em concentrações acima de $200 \mu \mathrm{g} \cdot \mathrm{mL}^{-1}$, o que corrobora com os resultados encontrados. A ação antimicrobiana dos sulfitos é dependente da penetração do $\mathrm{SO}_{2}$ através da parede celular do microrganismo, podendo causar ruptura da membrana citoplasmática, inativação da replicação do DNA e de enzimas vinculadas à membrana citoplasmática, ou reações individuais com componentes de vias metabólicas (Favero et al., 2011).

Tabela 2: Resultado das concentrações testadas para a determinação da CIM de conservantes alimentares

\begin{tabular}{c|c|c|c|c|c|c|c|c}
\hline \multirow{2}{*}{ Conservantes } & \multicolumn{7}{|c}{ Concentração dos conservantes $\left(\boldsymbol{\mu g} \cdot \mathbf{m L}^{-1}\right)$} \\
\cline { 2 - 9 } & 2.500 & 2.300 & 2.100 & 1.900 & 1.700 & 1.500 & 1.300 \\
\hline Sorbato de Potássio & $\mathrm{SCV}$ & $\mathrm{SCV}$ & $\mathrm{CV}$ & $\mathrm{CV}$ & $\mathrm{CV}$ & $\mathrm{CV}$ & $\mathrm{CV}$ \\
\hline Benzoato de sódio & $\mathrm{SCV}$ & $\mathrm{CV}$ & $\mathrm{CV}$ & $\mathrm{CV}$ & $\mathrm{CV}$ & $\mathrm{CV}$ & $\mathrm{CV}$ \\
\hline Conservantes & \multicolumn{7}{|c}{ Concentração dos conservantes $\left(\boldsymbol{\mu g} \cdot \mathrm{mL}^{-1}\right)$} \\
\cline { 2 - 9 } & 1.250 & 1.150 & 1.050 & 950 & 850 & 750 & 650 \\
\hline Metabissulfito de sódio & $\mathrm{SCV}$ & $\mathrm{CV}$ & $\mathrm{CV}$ & $\mathrm{CV}$ & $\mathrm{CV}$ & $\mathrm{CV}$ & $\mathrm{CV}$ \\
\hline Bissulfito de sódio & $\mathrm{SCV}$ & $\mathrm{CV}$ & $\mathrm{CV}$ & $\mathrm{CV}$ & $\mathrm{CV}$ & $\mathrm{CV}$ & $\mathrm{CV}$ \\
\hline $\mathrm{CV}-$ Crescimento visível & \multicolumn{7}{c|}{}
\end{tabular}

SCV - Sem crescimento visível

Por outro lado, a S. Typhimurium foi mais resistente a ação dos conservantes sorbato de potássio e benzoato de sódio, o que refletiu em uma CIM significativamente maior, chegando a $2.300 \mu \mathrm{g} . \mathrm{mL}-1$ e $2.500 \mu \mathrm{g} \cdot \mathrm{mL}-1$, respectivamente. Estes resultados representam o dobro da concentração requerida para os sulfitos. Uma possível explicação para a baixa atividade antimicrobiana destes dois conservantes está no $\mathrm{pH}$ do meio de cultura utilizado, que era aproximadamente 7,3. De acordo com Wang et al. (2018), com o aumento do pH extracelular, a ação antimicrobiana dos sorbatos diminui, pois apenas a forma não ionizada pode entrar nas células. Assim, a eficácia do sorbato de potássio diminui com a elevação do pH (Hwang et al., 2015). O mesmo ocorreu com o benzoato de sódio, já que ele é mais efetivo contra microrganismos patogênicos em pH ácido (Chen \& Zhong, 2018).

Apesar do mecanismo de ação antimicrobiana dos sorbatos não ser bem conhecida, considera-se que ela seja baseada na acidificação intracelular dos microrganismos (Bagar et al., 2009; Plumridge et al., 2004). Após penetrar na membrana celular, ele libera um próton que acidifica o citosol, levando à interrupção das vias catabólicas (Mira, Teixeira, \& Sá-Correia, 2010). Outro possível efeito do sorbato é a possibilidade de causar estresse celular, resultando em aumento da produção de toxinas (Fodil et al., 2018). 
Já o mecanismo de ação do benzoato de sódio está relacionado à sua conversão em ácido benzoico. Como esse ácido possui pKa de 4,2 (Chipley, 2005), estima-se que apenas 0,16\% de benzoato (base molar) estejam presentes como ácido benzoico em pH 7,0 (Chen \& Zhong, 2018). 0 fato de a atividade antimicrobiana de ácidos fracos depender da quantidade de moléculas de ácido não iônico capaz de penetrar livremente através da membrana plasmática (Brul \& Coote, 1999) fez com que uma maior quantidade de benzoato de sódio fosse requerida para inibir a bactéria. Assim, para manter o $\mathrm{pH}$ intracelular neutro, as bactérias precisam bombear prótons extras para fora da membrana, o que consome ATP e resulta em danos ou morte celular (Chen \& Zhong, 2018).

López et al. (2009), testando os conservantes metabissulfito de sódio, sorbato de potássio e benzoato de sódio obtiveram inibição da $S$. Typhimurium nas concentrações ( $\mu \mathrm{g} \cdot \mathrm{mL}^{-1}$ ) de $75,1.250$ e 1.000, respectivamente. A disparidade entre estes resultados e os aqui observados pode ser atribuído às diferenças na metodologia da CIM e às especificidades de cada cepa. Estes autores determinaram a CIM em meio sólido e acidificado, o que pode ter propiciado uma maior ação antimicrobiana dos conservantes, inclusive do metabissulfito e bissulfito de sódio. De acordo com Jay (2005), a teoria de que o $\mathrm{SO}_{2}$ molecular não dissociado é um dos responsáveis pela atividade antimicrobiana é sustentada pela alta eficiência desse composto em baixos valores de $\mathrm{pH}$.

De acordo com a legislação brasileira, a quantidade máxima permitida para cada aditivo varia conforme a aplicação e o tipo de alimento. Como os conservantes avaliados nesta pesquisa são muito utilizados em produtos de origem vegetal, devem seguir os limites máximos estabelecidos (LME) pela RDC no 08, de 8 de março de 2013 (BRASIL, 2013). Segundo a resolução, o LME, expresso em g. $100 \mathrm{~g}^{-1}$ ou $\mathrm{mL}^{-1}$, é de 0,01 (como $\mathrm{SO}_{2}$ residual) para metabissulfito e bissulfito de sódio, de 0,1 (como ácido sórbico) para o sorbato de potássio, e de 0,1 (como ácido benzoico) para o benzoato de sódio. Observa-se que a legislação tem o cuidado de expressar o LME em função da quantidade do composto ativo do conservante, e não da concentração do conservante em si. Como a concentração do composto ativo varia em função das características intrínsecas do alimento, tais como $\mathrm{pH}$, potencial Redox, atividade de água e composição química. Dessa forma, a utilização da CIM nos alimentos deve estar condicionada a tais características.

\section{CONCLUSÃO}

- Os conservantes alimentares inibiram o crescimento da bactéria $S$. Typhimurium, nas condições testadas.

- Metabissulfito e bissulfito de sódio foram os conservantes mais eficientes na inibição da $S$. Typhimurium, com CIM de $1.250 \mu \mathrm{g} \cdot \mathrm{mL}^{-1}$.

- As características intrínsecas do alimento devem ser levadas em consideração no momento de utilizar um conservante. 


\section{AGRADECIMENTOS}

O primeiro autor agradece ao Instituto Federal de Educação, Ciência e Tecnologia do Sertão Pernambucano - campus Salgueiro, pela concessão da bolsa de Iniciação Científica.

\section{REFERÊNCIAS BIBLIOGRÁFICAS}

Abdulmumeen, H. A., Risikat, A. N., \& Sururah, A. R. (2012). Food: Its preservatives, additives and applications. International Journal of Biological and Chemical Sciences, 1, 36-47.

Bagar, T., Altenbach, K., Read, N. D., \& Benčina, M. (2009). Live-cell imaging and measurement of intracellular $\mathrm{pH}$ infilamentous fungi using a genetically encoded ratio-metric probe. Eukaryotic Cell, 8 (5), 703-712.

BRASIL. (2013). Ministério da Saúde. Agência Nacional de Vigilância Sanitária - ANVISA. Resolução - RDC no 08, de 06 mar. de 2013. Dispõe sobre a aprovação de uso de aditivos alimentares para produtos de frutas e de vegetais e geleia de mocotó. Diário Oficial da União, Brasília, DF, 08 mar. de 2013, Seção 1.

BRASIL. (2011). Ministério da Saúde. Secretaria de Vigilância em Saúde. Manual técnico de diagnóstico laboratorial de Salmonella spp. Instituto Adolfo Lutz, Brasília, DF. 60 p.

BRASIL. (2001). Ministério da Saúde. Agência Nacional de Vigilância Sanitária - ANVISA. Resolução - RDC no 12, de 02 jan. de 2001. Aprova o regulamento técnico sobre padrões microbiológicos para alimentos. Diário Oficial da União, Brasília, DF, 10 jan. de 2001, Seção 1. 45 p.

BRASIL. (1997). Ministério da Saúde. Agência Nacional de Vigilância Sanitária - ANVISA. Portaria no 540, 27 de out. de 1997. Aprova o Regulamento Técnico: Aditivos Alimentares - definição, classificação e emprego. Diário Oficial da União, Brasília, DF, 28 out. 1997, Seção 1.

Brul, S., \& Coote, P. (1999). Preservative agents in foods: mode of action and microbial resistance mechanisms. International Journal of Food Microbiology, 50 (1-2), 1-17.

Cardoso, A. L. S. P., \& Tessari, E. N. C. (2015). Salmoneloses aviárias: Revisão. Revista Eletrônica Nutritime, 12 (03), $4049-4069$.

Chen, H., \& Zhong, Q. (2018) Antibacterial activity of acidified sodium benzoate against Escherichia coli 0157:H7, Salmonella enterica, and Listeria monocytogenes in tryptic soy broth and on cherry tomatoes. International Journal of Food Microbiology, 274, 38-44.

Chipley, J. R. (2015). Sodium benzoate and benzoic acid. In: Davidson, P. M., Sofos, J. N., \& Branen, A. I. (Eds). Antimicrobials in Food, 3.ed. Boca Raton: Taylor Francis Group, 11-48.

Damodaran, S., Parkin, K. L., \& Fennema, O. R. (2010). Química de Alimentos de Fennema, Porto Alegre: Artmed, $900 \mathrm{p}$. 
Evangelista, J. Tecnologia de alimentos. 2 ed. Rio de Janeiro: Atheneu, 2008. 652 p.

FAO - Food and Agriculture Organization of the United Nations (2016). Online Edition: Combined Compendium of Food Additive Specifications Available, 2016. Consultado em 20 de março de 2017. Disponível em http://www.fao.org/food/food-safety-quality/scientificadvice/jecfa/jecfaadditives/en/.

Favero, D. M., Ribeiro, C. S. G., \& Aquino, A. D. (2011). Sulfitos: Importância na indústria alimentícia e seis possíveis malefícios à população. Segurança Alimentar e Nutricional, 18 (1), 11-20.

FIB - Food Ingredients Brasil. (2011). Dossiê dos Conservantes, p. 28-51, 2011. Consultado em 20 de março de 2020. Disponível em http:// http://www.revista-fi.com/materias/186.pdf.

Filla, C. P. (2016). Principais conservantes utilizados em alimentos industrializados. Química alimentar. Consultado em 11 de fevereiro de 2020. Disponível em http://quimicalimentar.com.br/principais-conservantes-utilizados-em-alimentosindustrializados.

Fodil, S., Delgado, J., Varvaro, L., Yaseen, T., \& Rodríguez, A. (2018). Effect of potassium sorbate (E202) and the antifungal PgAFP protein on Aspergillus carbonarius growthand ochratoxin $A$ production in raisin simulating media. Journal of the Science of Food and Agriculture, 98, 57855794.

Forsythe, S. J. (2002). Microbiologia da Segurança Alimentar, Porto Alegre: Artmed, 424 p.

Franco, B.D.G.M.; Landgraf, M. (2005). Microbiologia dos alimentos. São Paulo: Atheneu, 196 p.

Helms, M., Ethelberg, S., Mølbak, K., \& DT104 Study Group (2005). International Salmonella Typhimurium DT104 infections, 1992-2001. Emerging infectious diseases, 11(6), 859-867.

Hwang, C. A., Huang, L., Juneja, V. (2015). Effect of acidified sorbate solutions on the lag-phase durations and growth rates of Listeria monocytogenes on meat surfaces. Journal of Food Protection, 78 (6), 1154-1160.

Jay, J. M. Microbiologia de Alimentos, Porto Alegre: Artmed. 2005. 711 p.

Lázaro, N. S., Reis, E. M. F., Pereira, C. S., \& Rodrigues, D. P. (2008). Gênero Salmonella: Características epidemiológicas e laboratoriais. Rio de Janeiro: IOC, 67 p.

Lidon, F. C., \& Silvestre, M. M. A. (2007). Industrias Alimentares - Aditivos e tecnologias. Escolar Editora: Lisbon, $360 \mathrm{p}$.

López, A. M. Q., Lima-Coelho, S. F., \& Lira, G. M. (2009). Efeito de diferentes concentrações de conservantes sobre o crescimento in vitro de bactérias veiculadas por alimentos. Instituto Adolfo Lutz, 68 (1), 49-57. 
Majowicz, S.E., Musto, J., Scallan, E., Angulo, F. J., Kirk, M., O’Brien, S. J., Jones, T. F., Fazil, A., \& Hoekstra, R. M. (2010). The global burden of nontyphoidal Salmonella gastroenteritis. Clinical Infectious Diseases, 50 (6), 882-889.

Mattick, K. L., Jorgensen, F., Legan, J. D. Lappin-Scott, H. M., \& Humphrey, T. J. (2000). Habituation of Salmonella spp. at reduced water activity and its effect on heat tolerance. Applied and Environmental Microbiology, 66 (11), 4921-4925.

Mira, N. P., Teixeira, M. C., \& Sá-Correia, I. (2010). Adaptive response and tolerance toweak acids in Saccharomyces cerevisiae: a genome-wide view. Omics: a journal of integrative biology, 14 (5), 525-540.

NCCLS (2003). Methods for Dilution Antimicrobial Susceptibility Tests for Bacteria That Grow Aerobically; Approved Standard-Sixth Edition. NCCLS document M7-A6 (ISBN 1-56238-486-4). Pennsylvania (USA).

Nemes, D., Kovács, R., Nagy, F., Tóth, Z., Herczegh, P., Borbás, A., Kelemen, V., Pfliegler, W. P., Rebenku, I., Hajdu, P. B., Fehér, P., Ujhelyi, Z., Fenyvesi, F., Váradi, J., Vecsernyés, M., \& Bácskay, I. (2020). Comparative biocompatibility and antimicrobial studies of sorbic acid derivates. European Journal of Pharmaceutical Sciences, 143, 2020, 105162.

Oliveira, T. L. C., Soares, R. A., \& Piccoli, R. H. (2013). A Weibull model to describe antimicrobial kinetics of oregano and lemongrass essential oils against Salmonella Enteritidis in ground beef during refrigerated storage. Meat Science, 93, 645-651.

Oliveira, T. M., Soares, N. F.; Paula, C. D., \& Viana, G. A. (2008). Uso de embalagem ativa na inibição do escurecimento enzimático de maçãs. Semina: Ciências Agrárias, 29 (1), 117-128.

Plumridge, A., Hesse, S. J. A., Watson, A. J., Lowe, K. C., Stratford, M., \& Archer, D. B. (2004). The weak acid preservative sorbic acid inhibits conidial germination and mycelial growth of Aspergillus niger through intracellular acidification. Applied and Environmental Microbiology, 70 (6), 3506-3511.

Rodrigues, K. R. M, \& Salay, E. (2000). Garantia de qualidade sanitária de ovos de galinha in natura, em unidade de alimentação e nutrição. Higiene Alimentar, 14 (73), 13-20.

Santos, L. R., Nascimento, V. P., \& Flores, M. L. (2002). Salmonella Enteritidis isoladas de amostras clínicas de humanos e de alimentos envolvidos em episódios de toxinfecções alimentares ocorridas entre 1995 e 1996 no Estado do Rio Grande do Sul. Higiene Alimentar, 16 (102-103), 93-99.

Shinohara, N. K. S., Barros, V. B., Jimenez, S. M. C., Machado, E. C. L., Dutra, R. A. F., \& Filho, J. L. L. (2008). Salmonella spp., importante agente patogênico veiculado em alimentos. Ciência \& Saúde Coletiva, 13 (5), 1675-1683.

Silva, M. M., \& Lidon, F. C. (2016). Food preservatives - An overview on applications and side effects. Emirates Journal of Food and Agriculture, 28(6), 366 - 373. 
Silva, N., Junqueira, V. C. A., Silveira, N. F. A., Taniwaki, M. H., Santos, R. F. S., \& Gomes, R. A. R. Manual de métodos de análise microbiológica de alimentos e água. 4.ed. São Paulo: Livraria Varela. 2010. 632 p.

Steenackers, H., Hermans, K., Vanderleyden, J., \& De Keersmaecker, S. C. J. (2012). Salmonella biofilms: an overview on occurrence, structure, regulation and eradication. Food Research International, 45(2), 502-531.

Tavechio, A. T., Ghilardi, A. C., Peresi, J. T., Fuzihara, T. O., Yonamine, E. K., Jakabi, M., \& Fernandes, S. A. (2002). Salmonella serotypes isolated from nonhuman sources in São Paulo, Brazil, from 1996 through 2000. Journal of Food Protection, 65 (6), 1041-1044.

Wang, J., Ma, M., Yang, J., Chen, L., Yu, P., Wang, J., Gong, D., Deng, S., Wen, X., \& Zeng, Z. (2018). In vitro antibacterial activity and mechanism of monocaprylin against Escherichia coli and Staphylococcus aureus. Journal of Food Protection, 81, 1988-1996.

World Health Organization (2016). Food and Agriculture Organization of the United Nations \& Joint FAO/WHO Expert Committee on Food Additives. Meeting (80th: 2015, Rome, Italy). Evaluation of certain food additives and contaminants: eightieth report of the Joint FAO/WHO Expert Committee on Food Additives. 109 p.

Yang, L., Liu, Y., Wu, H., Song, Z., Høiby, N., Molin, S., \& Givskov, M. (2012). Combating biofilms. FEMS Immunology and Medical Microbiology, 65 (2), 146-157.

\section{COMO CITAR ESTE ARTIGO:}

Ferreira, R.D., Soares, R.A., Carvalho, L.A., Silva, G.A., Oliveira, C.A., Silva, G.A. (2020). Determinação da concentração inibitória mínima de conservantes alimentares para o controle de Salmonella Typhimurium. Holos, 36(4), 1-14.

\section{SOBRE OS AUTORES}

\section{RAFAELA DIAS FERREIRA}

Estudante do Curso Superior de Tecnologia em Alimentos; Setor de Tecnologia de Alimentos do Instituto Federal de Educação, Ciência e Tecnologia do Sertão Pernambucano (IF-Sertão/PE). E-mail: rafadias31@outlook.com.

ORCID ID: http://orcid.org/0000-0003-3012-6088

\section{RODRIGO DE ARAÚJO SOARES}

Doutor em Ciência e Tecnologia de Alimentos pela Universidade Federal do Ceará (UFC); Professor do Curso Superior de Tecnologia em Alimentos; Setor de Tecnologia de Alimentos do Instituto Federal de Educação, Ciência e Tecnologia do Sertão Pernambucano (IF-Sertão/PE). E-mail: rodrigo.araujo@ifsertao-pe.edu.br. ORCID ID: http://orcid.org/0000-0003-2900-0373

\section{LUCIANA ALVES DE CARVALHO}

Estudante do Curso Superior de Tecnologia em Alimentos; Setor de Tecnologia de Alimentos do Instituto Federal de Educação, Ciência e Tecnologia do Sertão Pernambucano (IF-Sertão/PE). E-mail: 
lucianaalvesc762@gmail.com.

ORCID ID: http://orcid.org/0000-0001-5792-7593

\section{GABRIELA AYALA DA SILVA}

Estudante do Curso Técnico em Agropecuária; Instituto Federal de Educação, Ciência e Tecnologia do Sertão Pernambucano (IF-Sertão/PE). E-mail: g.ayaladasilva@gmail.com.

ORCID ID: http://orcid.org/0000-0002-0250-7978

\section{CRISTIANE AYALA DE OLIVEIRA}

Doutora em Ciência dos Alimentos pela Universidade Federal de Lavras (UFLA); Professora do Curso Superior de Tecnologia em Alimentos; Setor de Tecnologia de Alimentos do Instituto Federal de Educação, Ciência e Tecnologia do Sertão Pernambucano (IF-Sertão/PE). E-mail: cristiane.ayala@ifsertao-pe.edu.br.

ORCID ID: http://orcid.org/0000-0003-3552-4229

\section{GLÁUCIA ALVES E SILVA}

Doutora em Ciência do Solo pela Universidade Federal de Lavras (UFLA); Professora do Curso de Engenharia Florestal; Setor de Engenharia Florestal do Instituto Federal de Educação, Ciência e Tecnologia do Mato Grosso (IFMT). E-mail: glaucia.silva@cas.ifmt.edu.br.

ORCID ID: http://orcid.org/0000-0002-9798-6819

Editor(a) Responsável: Francinaide de Lima Silva Nascimento

Pareceristas Ad Hoc: Fábio Portella Corrêa de Oliveira e Neide Kazue Shinohara

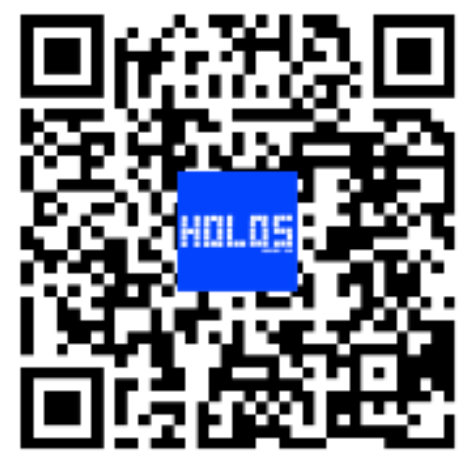

Recebido: 07 de maio de 2020

Aceito: 17 de junho de 2020

Publicado: 01 de julho de 2020 